\title{
Intensive Strategy Model and Implications for SME Business Performance
}

\author{
Nizar Alam Hamdani ${ }^{1}$, Sukma Nugraha ${ }^{2}$, Galih Abdul Fatah Maulani ${ }^{3}$, \\ \{galihafm@uniga.ac.id ${ }^{1}$, sukmanugraha@uniga.ac.id ${ }^{2}$, galihafm@uniga.ac.id ${ }^{3}$ \}
}

Universitas Garut, Indonesia, Jalan Jati No. 42 B Tarogong Garut, Indonesia

\begin{abstract}
SMEs can develop if properly managed. Just like big companies, SMEs should implement appropriate strategies to perform well. Using a quantitative approach, this study aims at developing an intensive strategy model through market penetration, market development, and product development and examining its implications for SME business performance. The samples were $57 \mathrm{SMEs}$ in Indonesia selected using a simple random sampling technique. Data analysis was performed using SEM-PLS. The results revealed that external factors have an impact on product development and market development, and internal factors have a major impact on market penetration. The intensive strategy has an impact on the performance of SMEs in such a way that the better the implementation of intensive strategy, the better the performance of SMEs. It was also revealed that it necessary for SMEs to demonstrate a capability to seize business opportunities, to demonstrate uniqueness, and to be innovative.
\end{abstract}

Keywords: intensive strategy, business performance, uniqueness, innovation.

\section{Introduction}

SMEs have been the subject of many studies. Researchers have studied SMEs in many countries in terms of financial aspect, marketing, human resources, operations, and so on [1]. SMEs played a very important role in driving the countries [2]. However, only with intensive strategies can SMEs survive and perform well [3]; [4]. Some previous studies have examined the relationship between intensive strategy implementation and SME performance [5]; [6][3].

It is also suggested that SME performance should be measured through grounded theory [7]. A previous study shows that the effect of strategy on SME performance can be measured through financial performance such as turnover, assets, ROI, and ROA [8]. Another previous study reported that the implementation of strategies such strategic planning, strategic formulation, strategic capability, marketing strategy, and generic strategy had influence on SME development [9].

intensive strategies consist of market penetration, market development, and product development. It is so-called because it takes intensive efforts to improve the competitive positioning of a company's existing products [10]. The product development strategy could improve business performance using financial performance and customer base as the indicators [11]. Likewise, marketing development was also reported to improve business performance [12][8]. 
The export performance of Garut leather industry products is restricted by limited supplies of raw materials and information [13].

Empirically, the domestic demand for leather reaches $20 \%$ of the total national production ranging from $60,000-70,000$ tons/year, some of which is supplied by leather industries in Sukaregang, Garut. With over 1,285 workers, current production of Sukaregang leather industries has only reached 1,500 tons/ month. Leather industries are currently diminishing due to their limited product development and inadequate market capability [14].

This study aimed at examining the effect of internal environments including human resource, finance, production and operation, and marketing on intensive strategy and its implications for leather industry business performance and of external environments including policy, social condition and culture, other institution, and economic condition on intensive strategy and its implications for leather industry business performance.

\section{Literature Review}

Strategic management refers to a process or a set of basic and comprehensive decisionmaking activities designed by the leader of an organization and their implementation procedures for all of its members in order to achieve the organizational objectives [15][16].

A market penetration strategy aims to increase the existing market share of products or services in the existing market with greater marketing efforts. This strategy is widely used in its own or in combination with other strategies. Market development includes the introduction of the existing products or services to new geographical areas. Product development refers to a strategy to increase sales by improving or modifying existing products or services [10]. This strategy requires research and development [17][18].

Environment analysis refers to the study of organizational environments that can affect the operations of a company and is done to quickly and precisely anticipate changes in the environments in question, both internal and external environments [15][19].

Strategic management is focused on the objective formulation, policy making, and human resources allocation.

A proper and measured strategy implementation is required in business [20]. A proper and well-planned strategy can facilitate organizational objective achievement [21].

\section{Methods}

This research used a quantitative explanatory design, aiming at explaining causal relationships between variables and testing the hypothesis. The respondents were 57 owners of small and medium scale leather industries in Garut. Measurement model and structural model tests were performed using SEM-PLS (Partial Least Square). The indicators for external variables included government policy, socio-cultural and economic condition, and aspects of related institutions, and the internal variables were measured using the following indicators: human resources, finance, production and operation, and marketing. The variables of intensive strategy included Market Development Strategy, Product Development Strategy and Market Penetration Strategy. SME performance was measured using total assets, return on investment (ROI), sales volume, employment size, capital employed, market share, customer satisfaction, productivity, delivery time, and employee turnover. 


\section{$4 \quad$ Results and Discussion}

PLS Algorithm calculation shows the value of each indicator that can be interpreted as follows:

1. The path coefficient from Internal Environment (X1) to the latent variable Intensive Strategy (Y) was 0.643 , meaning that the influence of X1 on Y was 0.643

a. The loading for the indicator Human Resources (X11) was 0.928, meaning that $\mathrm{X} 1$ contributes to $\mathrm{X} 11$ as much as 0.928 .

b. The loading for the indicator Finance (X12) was 0.946, meaning that X1 contributes to X12 as much as 0.946 .

c. The loading for the indicator Production and Operation (X13) was 0.459, meaning that $\mathrm{X} 1$ contributes to $\mathrm{X} 13$ as much as 0.459 .

d. The loading for the indicator Marketing (X14) was 0.533, meaning that X1 contributes to $\mathrm{X} 14$ as much as 0.533 .

2. The path coefficient from External Environment (X2) to the latent variable intensive strategy (Y) was 0.356 , meaning that the influence of X1 on Y was 0.356 .

a. The loading for the indicator Other Institutions (X21) was 0.574, meaning that X2 contributes to X21 as much as 0.574 .

b. The loading for the indicator Policy (X22) was 0.798 , meaning that X2 contributes to $\mathrm{X} 22$ as much as 0.798 .

c. The loading for the indicator Socio-Cultural Condition (X23) was 0.960, meaning that X2 contributes to X23 as much as 0.960 .

d. The loading for the indicator Economic Condition (X24) was 0.960, meaning that $\mathrm{X} 2$ contributes to $\mathrm{X} 24$ as much as 0.960 .

3. The path coefficient from Intensive Strategy (Y) to the latent variable Business Performance $(\mathrm{Z})$ was 0.910 , meaning that the influence of $\mathrm{Y}$ on $\mathrm{Y}$ was 0.910.

a. The loading for the indicator Financial Performance (Y1) was 0.844, meaning that $\mathrm{Y}$ contributes to $\mathrm{Y} 1$ as much as 0.844 .

b. The loading for the indicator Non-Financial Performance (Y2) was 0.945, meaning that $\mathrm{Y}$ contributes to $\mathrm{Y} 2$ as much as 0.945 .

PLS Algorithm shows that Production and Operation (X13), Marketing (X14), other Institutions (X21), and Market Development Strategy (Y1) have loading factors below 0.6. These items X13, X14, X21 and Y1 was then removed from the model. The resulting model is illustrated in Figure 1. 


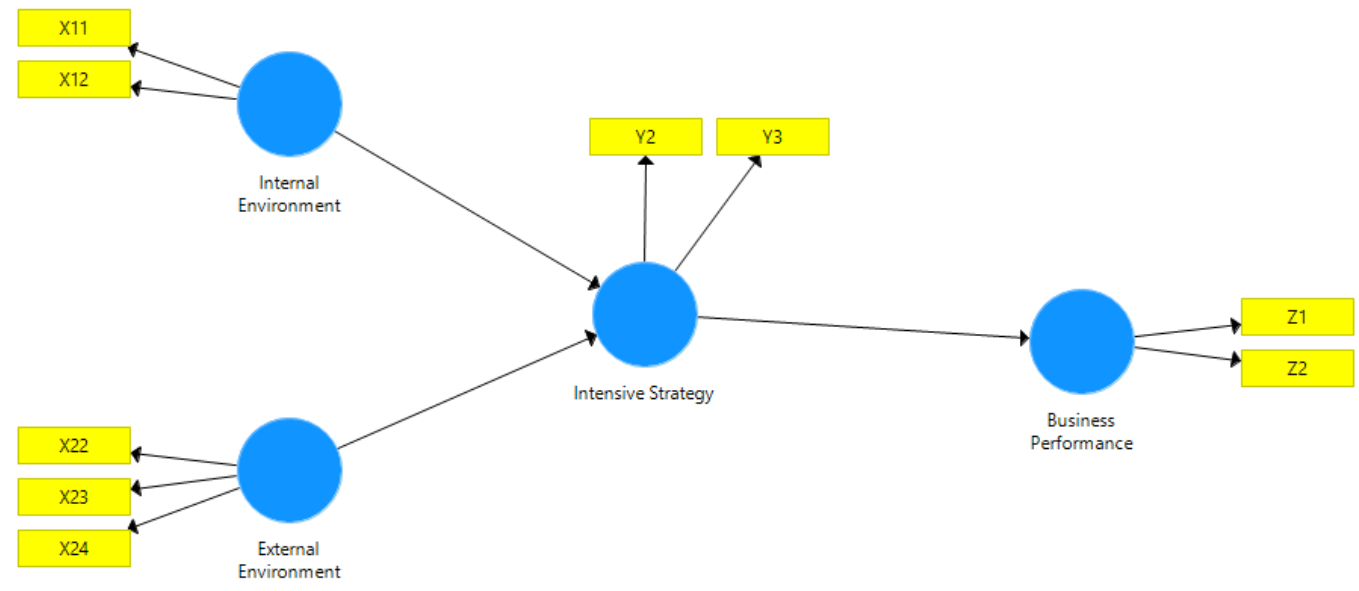

Fig 1. Results of PLS Algorithm without X13, X14, X21 and Y1

The hypothesis testing was carried out through outer model testing using bootstrapping method. The result is illustrated in Figure 2.

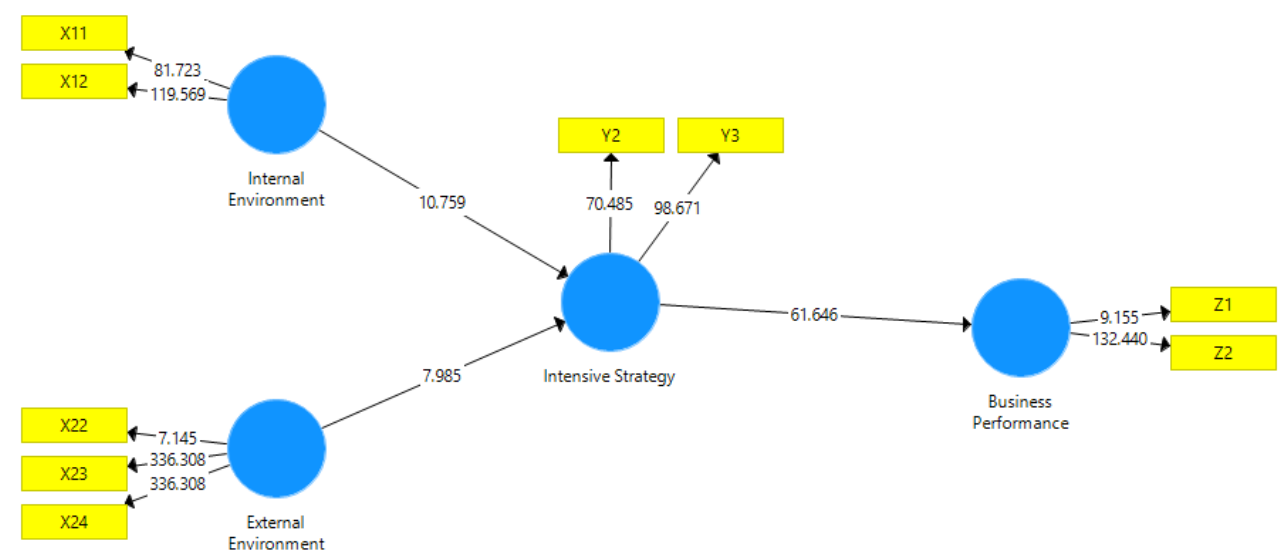

Fig 2. Model after bootstrapping 
The bootstrapping also generated data as illustrated in Figure 3.

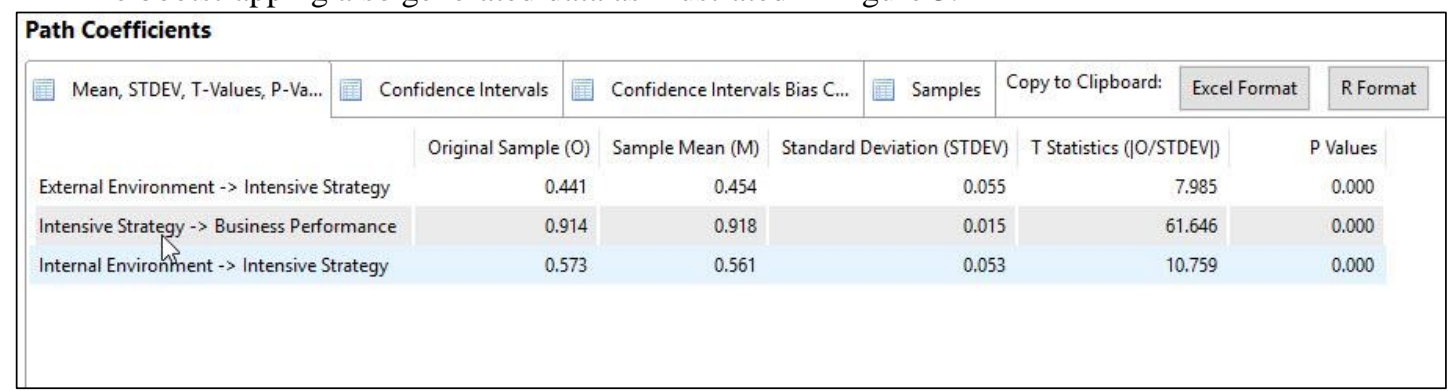

Fig 3. Path Coefisients

Based on path Coefficient calculation, the relationship between Internal Environment (X1) and Intensive Strategy (Y) was significant, with a statistical-T value of 10.759 (>1.66). The original sample estimate value was positive, meaning that the relationship between $\mathrm{X} 1$ and $\mathrm{Y}$ was positive. To conclude, Internal Environment has significant influence on Intensive Strategy.

The relationship between Intensive Strategy (Y) and Business Performance (Z) was also significant, indicated by a statistical-T value of 61.646 (>1.66). Since the original sample estimate value was positive, this Y-Z relationship was also positive. In other words, Intensive Strategy has significant influence on Business Performance.

Similarly, there was also a significant positive relationship between External Environment (X2) and Intensive Strategy (Y) with a statistical-T value of 7.985 (>1.66) and original sample estimate value of 0,441 . Therefore, External Environment has significance influence on Intensive Strategy.

\section{Conclusion}

This study has found that internal and external environments had influence on intensive strategies and in turn affected SME business performance. This finding leads to a conclusion that prior to applying intensive strategies, leather industries in Garut should begin with the product development, which is the first step to market development. It is critical for small and medium scale industries to create product uniqueness in order to exhibit that they have values and competitiveness. Government supports through mentoring, funding, and market development are required to develop leather industries in Garut.

\section{References}

[1] G. Berisha and J. S. Pula, "Defining Small and Medium Enterprises : a critical review," Acad. J. Business, Adm. Law Soc. Sci., vol. 1, no. 1, pp. 17-28, 2015.

[2] M. Hu, "Smes and economic growth: entrepreneurship or employment ming-wen hu," ICIC Express Lett., vol. 4, no. 6, pp. 2275-2280, 2010.

[3] Ö. Ç. Bozkurt and A. Kalkan, "Business Strategies of SME' s, Innovation Types and Factors Influencing Their Innovation : Burdur Model," EGE Acad. Rev., vol. 14, no. 2, 
pp. 189-198, 2014.

[4] S. Sarosa and D. Zowghi, "Strategy for Adopting Information Technology for SMEs: Experience in Adopting Email within an Indonesian Furniture Company," Electron. J. Inf. Syst. Eval., vol. 6, no. 2, pp. 165-176, 2003.

[5] N. A. Hamdani, "Building Knowledge Creation For Making Business Competition Atmosphere in SME of Batik," Manag. Sci. Lett., vol. 8, pp. 667-676, 2018.

[6] S. F. Slater, E. M. Olson, and C. Finnegan, "Business strategy , marketing organization culture , and performance," pp. 227-242, 2011.

[7] G. Chong, "Measuring performance of small-and-medium sized enterprises: the grounded theory approach," J. Bus. Public Aff., vol. 2, no. 1, pp. 1-10, 2008.

[8] S. Karel, P. Adam, and P. Radomír, "Strategic Planning and Business Performance of Micro , Small and Medium-Sized Enterprises," J. Compet., vol. 5, no. 4, pp. 57-72, 2013.

[9] N. A. Hamdani and W. Susilawati, “Application of Information System Technology and Learning Organization to Product Innovation Capability and Its Impact On Business Performance of Leather Tanning Industry,” Int. J. Eng. Technol., vol. 7, pp. 393-397, 2018.

[10] D. and W. L. T. Hunger, Strategic Management and Business Policy Toward Global Sustainability, 13th Editi. New Jersey: Pearson Prentice Hall, 2017.

[11] S. C. Koks and J. M. Kilika, "Towards a Theoretical Model Relating Product Development Strategy , Market Adoption and Firm Performance : A Research Agenda," J. Manag. Strateg., vol. 7, no. 1, pp. 90-97, 2016.

[12] M. A. Adesola and I. O. Oyewale, "Impact of Marketing Strategy on Business Performance A Study of Selected Small and Medium Enterprises ( Smes ) In," J. Bus. Manag., vol. 11, no. 4, pp. 59-66, 2013.

[13] Pemda, "Profil Ekonomi Kabupaten Garut," Ekonomi, 2015. .

[14] G. D. Goverment, "Performarce Report on Garut," Garut, 2016.

[15] E. W. Mainardes, J. Ferreira, and M. L. Raposo, "Strategy And Strategic Management Concepts: Are They Recognised By Management Students?," Bus. Adm. Manag. Strateg., vol. 1, no. 17, 2014.

[16] H. K. S. H. Athapaththu, "An Overview of Strategic Management: An Analysis of the Concepts and the Importance of Strategic Management," vol. 6, no. 2, pp. 124-127, 2016.

[17] Drucker and F. Peter, Innovation and Entrepreneurship, Practice and Principles. New York: Harper \& Row Publisher, 1985.

[18] M. M. Keupp, M. Palmié, and O. Gassmann, "The Strategic Management of Innovation :," 2011.

[19] C. Lee and J. M. Pennings, "Internal Capabilities , External Networks , and Performance: A Study on Technology-Based Ventures Internal Capabilities , External Networks , and Performance : A Study on,” vol. 22, pp. 615-640, 2001.

[20] A. Haythem, "The Role of Strategic Planning in Performance Management," Int. J. Multi Discip. Res., vol. 2, no. 3, 2015.

[21] A. Clarke, M. Fuller, A. Clarke, and M. Fuller, "Collaborative Strategic Management: Strategy Formulation and Implementation by Multi-Organizational Cross-Sector Social Partnerships," no. 2010, pp. 85-101, 2011. 
